\title{
CARACTERIZACIÓN BOTÁNICA DEL VOLCÁN QUILOTOA
}

\section{Síntesis}

Este trabajo se realizó en la provincia de Cotopaxi, en el volcán Quilotoa, en cuyo interior se encuentra una laguna, en las coordenadas $78^{\circ}, 54^{\prime}, 06^{\prime \prime}$ W y $00^{\circ}, 51^{\prime}, 21^{\prime \prime} S$, a 3980 msnm la parte más alta y a $3540 \mathrm{msnm}$ el nivel del agua. Esta zona corresponde a un páramo herbáceo. Para la investigación se realizaron observaciones y colecciones generales. La identificación se la hizo en el Herbario Nacional del Ecuador QCNE.

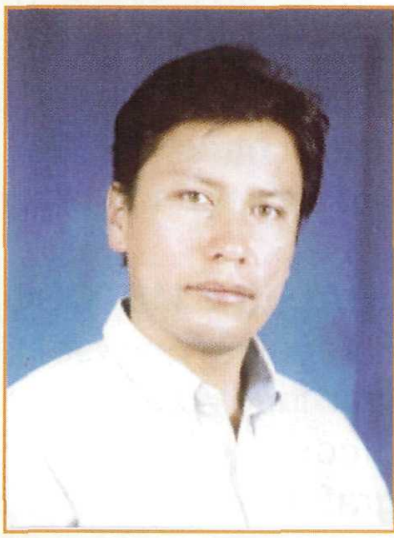

* Ong. Marco Cerna

Se registraron 31 familias y 62 géneros correspondientes a 85 especies, de las cuales 14 especies son introducidas 56 nativas, de estas cuatro son endémicas y 11 no pudieron ser identificas. Las familias más importantes por el número de especies fueron: Asteraceae, Poaceae y Fabaceae. Dentro de las especies en peligro, de acuerdo con el libro rojo de las plantas endémicas del Ecuador 2000, tenemos: Aristeguietia glutinosa, Gentianella cerastioides, Cajaphora aequatoriana, Castilleja nubígena.

Comparando con zonas similares hay un bajo número de especies que evidencian el alto grado de alteración que ha sufrido por causas antropogénicas.

\section{INTRODUCCIÓN}

Una figura muy interesante en los altos Andes ecuatorianos es la del volcán Quilotoa y en especial la laguna que aloja en su caldera. Esta ha sido estudiada desde el tiempo de los geodésicos franceses en el siglo XVIII y más detenidamente, en el tiempo de los politécnicos, en la década de los setenta del siglo (XIX): Wolf, Dressel, Wilhem Reiss. Un estudio de las aguas fue realizado por el químico Luis Dressel (Acosta-Solís, 1984). Cerón (1994) publica un estudio llamado Ednobotánica del Quilotoa, donde analiza las especies útiles de la zona. Actualmente es una zona de interés turístico, debido a su majestuoso paisaje, la presencia de grupos indígenas de la zona y a la relativa facilidad para llegar al sitio.

\section{OBJETIVOS}

- Identificar la flora existente en el volcán Quilotoa.

- Establecer los grupos más importantes de plantas y las especies endémicas, nativas e introducidas.

\section{ÁREA DE ESTUDIO}

En la Cordillera Occidental en la provincia de Cotopaxi, encontramos la laguna del Quilotoa, que ocupa un cráter volcánico, el borde superior del cráter llega a los 3980 msnm y el nivel del agua está a 3540 msnm. Este volcán muestra huellas de la 
actividad en los siglos pasados (Acosta-Solís, 1984). La laguna del Quilotoa se encuentra en las coordenadas $78^{\circ}, 54^{\prime}, 06^{\prime \prime}$ W y $00^{\circ}, 51^{\prime}, 21^{\prime \prime S}$ (IGM, 1972). Esta formación natural de la Sierra ecuatoriana corresponde a un páramo herbáceo (Valencia y otros, 1999). Se puede llegar al borde del cráter en vehículo por un carretero de segundo orden, ingresando por la vía Latacunga-Zumbahua-Jataló.

\section{MATERIALES Y MÉTODOS}

Los materiales que se utilizaron fueron: podadora de mano, cinta de marcaje, marcador indeleble, sacos plásticos, periódicos, piolas, estufa, bibliografía especializada y las muestras del Herbario QCNE.

Se realizaron observaciones y colecciones generales en el mes de julio de 2002. Para esto se circunvaló el cráter del volcán y el interior de la caldera en los lados sur, occidental y norte. El trabajo se realizó con la ayuda de nativos del lugar. La identificación se hizo mediante comparación de las especies colectadas con las muestras del Herbario Nacional del Ecuador QCNE.

\section{RESULTADOS Y DISCUSIÓN}

Se registraron 31 familias y 62 géneros correspondientes a 85 especies, de las cuales 14 fueron introducidas, 56 nativas; de estas 4 son endémicas y 11 no pudieron ser identificas.

Las familias más importantes por el número de especies: Asteraceae (17 sp), Poaceae (15 sp), Fabaceae (7 sp), Scrophulariaceae (5 sp) y Lamiaceae (3). Gráfico $\mathrm{N}^{\circ} 1$, Lo que evidencia una similitud con zonas parecidas del Ecuador descritas por Ulloa \& Jorgensen (1995), Valencia y otros (1999) y Neill (1999).

Dentro de las especies en peligro, de acuerdo con el libro rojo de las plantas endémicas del Ecuador 2000, tenemos: Aristeguietia glutinosa, Gentianella cerastioides, Castilleja nubígena y Cajaphora aequatoriana es una especie que no está registrada en el Catálogo de plantas vasculares del Ecuador.

De las 85 especies registradas en este estudio, 35 ya fueron descritas por Cerón (1994), cuando encontró 82 especies útiles en este lugar. Además, describió 47 especies que no son descritas en el presente trabajo. 50 adicionales son descritas en esta investigación. Dando un total de 132 especies anotadas en los dos estudios para este sector. 
Familia con más especies

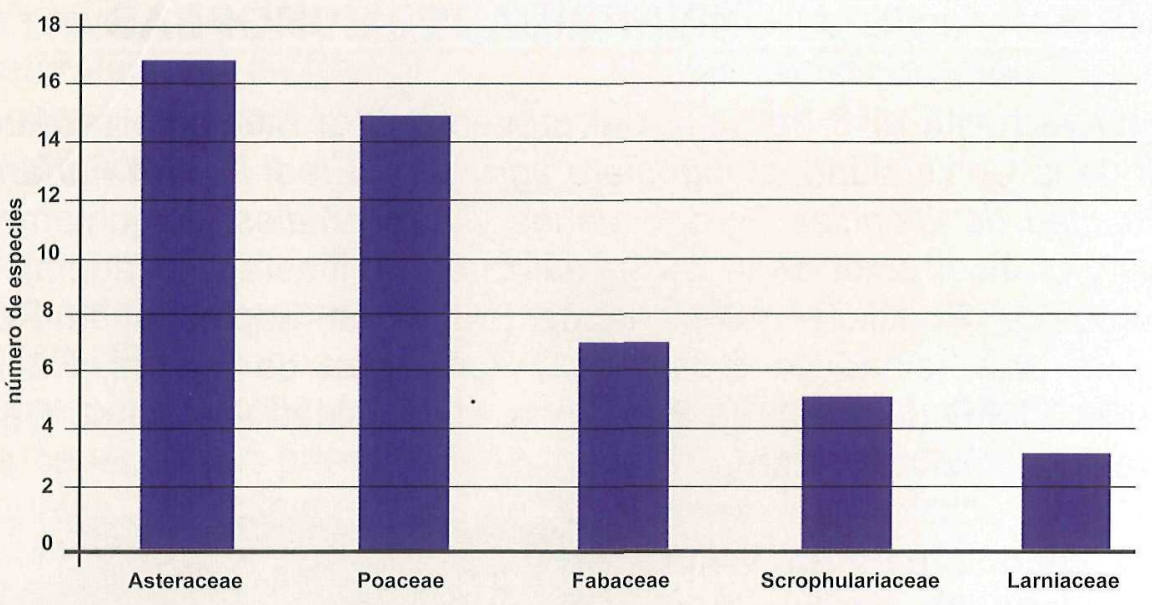

\section{CONCLUSIONES}

Esta zona registra un bajo número de especies, comparada con zonas similares, lo que muestra el alto grado de alteración que ha sufrido por causas antropogénicas. Se evidencia un claro dominio de familias que también lo hacen en zonas similares de páramo herbáceo.

\section{RECOMENDACIONES}

Es necesario y urgente realizar un plan de manejo de la zona con el fin de controlar la desorganizada visita de turistas, el uso inadecuado del suelo agrícola, el pastoreo sobrecargado y la introducción de chivos.

Se debe proceder a recuperar la zona urgentemente con el fin de parar la erosión del suelo. Para esto se pueden utilizar las especies nativas registradas en este estudio y las de zonas similares.

\section{BIBLIOGRAFÍA}

ACOSTA-SOLÍS, M.: Los páramos andinos del Ecuador. Publicaciones Científicas MAS. Quito, 1984.

IGM: Índice Toponímico de la republica del Ecuador. Tomo VIII. Quito, 1972.

JORGENSEN P. \&. LEÓN-YÁNEZ, S.: Catálogo de plantas vasculares del Ecuador. Missouri Botanical Garden Press. 1999.

NEILL, D.: Vegetación en Jorgensen P. \& S. León-Yánez. Catálogo de plantas vasculares del Ecuador. Missouri Botanical Garden Press. página 23.

ULLOA, C. y JORGENSEN, P.: Árboles y arbustos de los Andes del Ecuador. Ediciones Abya-yala. Quito. 1995.

VALENCIA, R. y otros. Libro rojo de las plantas endémicas del Ecuador 2000. Herbario QCA. Pontificia Universidad Católica del Ecuador. Quito. 2000.

VALENCIA, R. y otros: Las formaciones naturales de la Sierra del Ecuador. Sierra, R. (ed.) Propuesta preliminar de un sistema de clasificación de vegetación para el Ecuador continental. Proyecto INEFAN/GEF-BIRF y Ecociencia. 1999.

* Catedrático de ingeniería agropecuaria. Guasaganda-Cotopaxi 